\title{
Adaptability of Dolichos Bean (Lablab purpureus (L.) Sweet) Recombinant Inbred Lines across Locations Representing Eastern and Southern Dry Zones of Karnataka
}

\author{
Pranesh, S. Ramesh*, N. Marappa, P. Mahadevu ${ }^{1 *}$ and \\ M.S.P. Kanavi ${ }^{2}$ \\ Department of Genetics and Plant Breeding \\ College of Agriculture \\ Gandhi Krishi Vignana Kendra \\ University of Agricultural Sciences \\ Bengaluru, India
}

\begin{abstract}
Genotype and environment interaction offers opportunities for selection of genotypes exhibiting favorable responses to only a few locations or of genotypes with low frequency of poor yield across years in a given location. Ten promising recombinant inbred lines (RILs) were evaluated for dry seed yield/plant at four locations representing eastern and southern dry zones of Karnataka, India during 2017 rainy season to detect and characterize RIL and location interaction and to identify those with location specific and/or wide adaptation. Additive main Effect and Multiplication Interaction (AMMI) model and genotype by-environment interaction (GGE) biplot were used for objective and graphical (visual) assessment of patterns of adaptability of the selected RILs. Recombinant inbred lines 77 and 12 were the best performers at Bengaluru and Hassan, respectively and RIL 80 and RIL 111 were the best performers at Chintamani and Mandya regions respectively. Based on both graphical and objective assessments, RIL 52 and RIL 96 were found to be better adapted across all the test locations with relatively high dry seed yield/plant.
\end{abstract}

Keywords: Adaptability, Dolichos bean, genotype and location interaction, RILs

\section{INTRODUCTION}

Dolichos bean (Lablab purpureus (L.) Sweet) is one of the underutilized grain legume crops as evidenced by the smaller extent of cultivation (Ramesh and Byregowda, 2016). The development of widely adaptable and stable high yielding varieties can offer competitive edge to dolichos bean enabling its popularity (Ramesh and Byregowda, 2016). Genotypes very often differ in their responses to production due to temporal and spatial variations in the growing environment. This result in significant crossover genotypexyear and genotypexlocation interactions (GLI) (Annicchirarico, 1992). To optimize economic benefits of crop production, crop varieties should temporally and spatially consistent in performances and these performances are referred to as stability and adaptability, respectively (Lin and Binns, 1988). However, cross-over genotypexenvironment interaction (GEI) leads to inconsistent performances of many high yielding crops and this challenges plant breeders and variety

\footnotetext{
Zonal Agricultural Research Station (ZARS), VC Farm, Mandya, UAS, Bengaluru, India

Department of Genetics and Plant Breeding, College of Agriculture, Hassan, UAS, Bengaluru, India

* Corresponding author: ramesh_uasb@rediffmail.com
} 
recommendations (Annicchirarico, 1992). Nevertheless, GEI offer opportunities for selection of genotypes exhibiting site specific and time specific favorable responses. It is widely acknowledged that only GLI could be exploited by selecting for specific adaptation or by growing specifically adapted genotypes (Annicchirarico, 1992). This is because, from a farmer's point of view, location is a constant factor and GLI effects are repeatable in time (Annicchirarico, 1992). Recombinant inbred lines (RILs) could be used as cultivars for commercial production if better than the check. The present study was carried-out with an objective of identifying dolichos bean RILs which showing different levels of adaptability.

\section{METHODOLOGY}

\section{Evaluation of experimental material}

The material for the present study consisted of ten promising RILs which are derived from HA 10-8 × RIL 3-180. These RILs differed for plant height, days to $50 \%$ flowering, pod shape, pod size and seed size. The seeds of these genotypes are being maintained at the Department of Genetics and Plant breeding (GPB), College of Agriculture (CoA), University of Agricultural Sciences (UAS), Bengaluru, India.

The seeds of ten RIL were sown in randomized complete block design (RCBD) with two replications at four locations viz., GKVK, Bengaluru, Agricultural Research Stations (ARS)Chintamani (representing eastern dry zone of Karnataka), Zonal Agricultural Research station (ZARS) Mandya and College of Agriculture Hassan (representing southern dry zone of Karnataka) during 2017 rainy season. Latitude, longitude and average rainfall of these test locations are furnished in Table 1 . A total of 10 plants were maintained per replication in each RIL. Each RIL was sown in a single row of $3 \mathrm{~m}$ length with row-to-row spacing of $0.45 \mathrm{~m}$. After 10 days of sowing, seedlings of each RIL were thinned to maintain a spacing of $0.3 \mathrm{~m}$ between the plants within a row. Recommended management practices were followed during the crop growth period to raise a healthy crop. Data were recorded on five randomly chosen plants in each replication on dry seed yield/plant following the published protocol (Byregowda et al., 2015).

Table 1. Longitude, Latitude and average rainfall of the test locations

\begin{tabular}{lccc}
\hline Test location & Longitude (N) & Latitude (E) & Average rainfall (mm) \\
\hline GKVK, Bengaluru & $13^{\circ} 05^{\prime \prime}$ & $77^{\circ} 34^{\prime \prime}$ & 915.8 \\
ARS, Chintamani & $13^{\circ} 40^{\prime \prime}$ & $78^{\circ} 05^{\prime \prime}$ & 630 \\
ZARS, Mandya & $19^{\circ} 00^{\prime \prime}$ & $76^{\circ} 00^{\prime \prime}$ & 1054 \\
College of Agriculture & $13^{\circ} 08^{\prime \prime}$ & $76^{\circ} 18^{\prime \prime}$ & 852 \\
Hassan & & & \\
\hline
\end{tabular}

\section{Statistical analysis}

The means of each RILs were analyzed using Additive Main effects and Multiplicative Interaction (AMMI) model (Gouch and Zobel, 1988) to detect and characterize the patterns of genotypexlocation interaction (GLI). The additive main effects of RIL and locations were fitted by univariate ANOVA followed by fitting GLI by principal component (PC) analysis based AMMI II model (Gouch and Zobel, 1988). The parameters of AMMI model were estimated using least square principle implemented by GENSAT software, version 12. 


\section{Interpretation of GLI patterns of RILs}

The visual criterion was based on Genotype + Genotype $\times$ location (GGL) biplot (Yan et al., 2000). Objective criterion was based on the estimates of AMMI Adaptability value (AAV) (Purchase et al., 2000) and Adaptability Index (AI) (Farshadfar, 2011). GGL biplot methodology, which is a combination of AMMI bi-plot and GGL concepts (Yan et al., 2000) was used for visual interpretation of patterns of GLI. There are numerous ways to use a GGL biplot. However, four views of the GGL bi-plot are most relevant (Segherloo et al., 2010). These are (1) polygon view of GGL bi-plot based on symmetrical scaling for determining 'which-won-where' pattern of genotypes with test locations, (2) discriminating and representativeness of test locations view of GGL bi-plot, (3) average-environment coordination (AEC) view of GGL bi-plot based on genotype-focused scaling for raking of the test genotypes relative to ideal genotype; the ideal genotype is the one whose point is located in the center of concentric circles in the GGL bi-plot and (4) AEC view of bi-plot based on environment-focused scaling for interpreting mean performance of the genotypes $v s$. their adaptability patterns. To facilitate an objective method of identifying RILs with specific/wide adaptation across locations, the AMMI stability value (ASV) was estimated (Purchase et al., 2000). Higher magnitude of estimates of ASV indicates specific adaptation, while lower magnitude of ASV indicates wide adaptation (Purchase et al., 2000). Adaptability index (AI) which incorporates both mean dry seed yield/plant and adoptability in a single criterion (Farshadfar, 2011) was estimated as SI= RASV+ RY where, RASV is rank of the RILs based on ASV and RY is the rank of genotype based on mean dry seed yield/plant over four locations. The RILs with low AI were regarded as those with high mean dry seed yield/ plant and wide adaptation.

\section{RESULTS AND DISCUSSION}

\section{Results of AMMI model}

The per cent variance attributable to GLI towards total variability of the RIL was higher than that attributable to main effects of RIL and locations for dry seed yield/plant (Table 2). Thus, total variation of RILs for dry seed yield/plant was predominantly attributable to differential performance of RILs across locations rather than RILs performance and influence of location. IPCA I and IPCA II explained most of the variation attributable to GLI.

Table 2. AMMI ANOVA of dolichos bean recombinant inbred lines (RILs) derived from HA 10-8 $\times$ RIL 3-180 for dry seed yield/plant

\begin{tabular}{lccccc}
\hline Source & $\begin{array}{c}\text { Degrees of } \\
\text { freedom }\end{array}$ & $\begin{array}{c}\text { Mean sum } \\
\text { of squares }\end{array}$ & 'F' Statistic & $\mathbf{P} \geq \mathbf{F}$ & $\begin{array}{c}\% \\
\text { variation }\end{array}$ \\
\hline RILs & 09 & 11.65 & 03.12 & $1 \times 10^{-4}$ & 04.35 \\
Locations & 03 & 245.76 & 37.15 & $1 \times 10^{-3}$ & 30.63 \\
RILs $\times$ location & 27 & 52.01 & 13.92 & $1 \times 10^{-6}$ & 58.33 \\
IPCA 1 & 11 & 90.34 & 24.18 & $1 \times 10^{-3}$ & 70.74 \\
IPCA 2 & 09 & 35.96 & 09.63 & $1 \times 10^{-5}$ & 23.05 \\
Residual & 07 & 12.40 & 03.32 & $1 \times 10^{-4}$ & \\
Error & 36 & 03.74 & & & \\
\hline
\end{tabular}




\section{Discriminativeness and representativeness view of GGL bi-plot}

Assessment of discriminating and representativeness of test locations is based on the length of environment (location) vectors, and the angle between the test location vectors and average environment coordination (AEC) in the GGL bi-plot. The lines that connect the test location points to the origin of GGL bi-plot are referred to as location vectors. A single-arrowed line (ray) passing through the origin of the bi-plot and the average of the environments (i.e. the average of three locations) is referred as AEC. Shorter the location vectors, lower is the discriminating ability of the location; longer the vector, higher is the discriminating ability of the location. A test location that has a smaller angle with AEC is more representative of test locations. The cosine of the angle between the vectors of two locations approximates the correlation between them. While acute angle between the vectors of test locations indicate positive correlation or similarity between them, obtuse and right angles indicate negative correlation or dissimilarity, and no relationship respectively between the test locations. In the present study, while the vectors of the three locations (Mandya, Bengaluru and Chintamani) were longer and almost of equal length, that of Hassan was shorter (Figure 1a). Clearly, Mandya, Bengaluru and Chintamani were discriminative while Hassan was less discriminative. Similarly, the higher acute angle between the vectors of Hassan and Bengaluru than those of Mandya and Chintamani; Bengaluru and Chintamani; Hassan and Chintamani and Hassan Bengaluru. The closer/ acute angle of the vector of Mandya to AEC than those of Chintamani, Hassan and Bengaluru suggested that Mandya location is more representative than remaining locations. Thus, RILs could be evaluated in Mandya, Bengaluru and Chintamani and Hassan could be avoided to elicit the same information as could be obtained from all the locations.
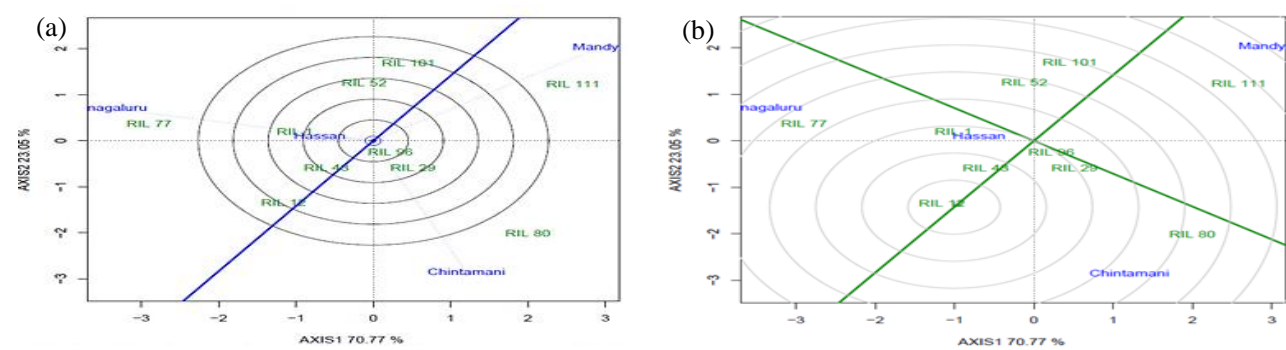

Figure 1. (a) Discriminative versus representativeness view of GGL (b) average environmental coordination view of GGL biplot

\section{Ranking of genotypes relative to ideal genotype}

An ideal genotype should have both high mean performance and high stability across environments. An ideal genotype is the one which is located in inner most concentric circles in the GGL bi-plot. The genotypes located closer to the "ideal genotype" are more desirable than others. In the present study, RIL 12 was identified as ideal genotype as it is located in the center of concentric circles (Figure 1b). The RILs, RIL 43, RIL 1, RIL 96 and RIL 29 were regarded as nearly ideal genotypes as they located relatively closer to RIL 12 in the GGL biplot. Since dry seed is consumable product, RIL 12, RIL 43, RIL 96, RIL 29 and RIL1 could be preferentially used in breeding dolichos bean varieties with wide adaptation. 


\section{Mean performance versus adaptability}

The genotypes with their points located towards arrow of AEC are considered to exhibit high mean performance. On the contrary, the genotypes with their points located opposite to AEC arrow are considered to exhibit lower performance. Further, the relative lengths of projections of the genotypes from AEC are indicative of their relative adaptability. The greater the absolute length of the projections of genotypes, greater would be their poor adaptability (Yan and Kang, 2002). In the present study, the closer location of points of RIL 12, RIL 43 and RIL 96 over other RILs indicated that they are widely adapted to four locations with relatively high average dry seed yield/plant (Figure 2a).

\section{Which-won-where pattern of genotypes}

One of the features of GGL bi-plot is its ability to show which - won - where pattern of a genotype. This feature is shown by polygon view of the GGL bi-plot. The genotypes located on the vertices of the polygon perform either the best or poorest in one or more locations (Yan et al., 2000). The equality lines divide the bi-plot into sectors. The vertex genotype in each sector is the winning genotype at locations whose markers (point) fall into the respective sector (Yan et al., 2000). Locations within the same sector share the same winning genotype, and locations in different sectors have different winning genotypes, thus polygon view of a GGL bi-plot indicates presence or absence of cross-over GLI (Yan and Rajcan, 2002). In the present study, the genotypes RIL 77 and RIL 12 were best performers at Bengaluru and Hassan, respectively (Figure 2b). RIL 80 was the best performer at Chintamani and RIL 111 was the best performer at Mandya.
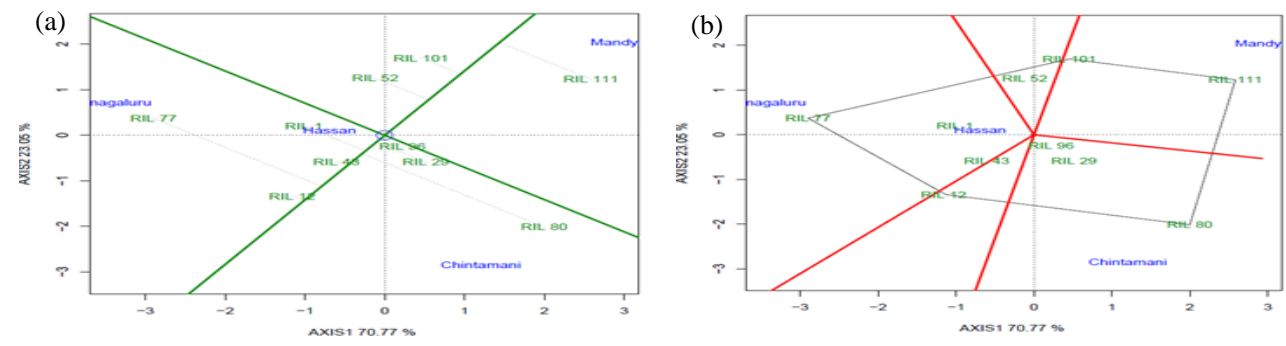

Figure 2. (a) Average environment coordination (AEC) view and (b) polygon view of GGL bi-plot

\section{Adaptability of Dolichos Bean}

The estimate of AMMI adaptability value (AAV) is a useful parameter for objective assessment of adaptability of the genotypes. Lower the magnitude of AAV, higher is the adaptability of the genotypes. In the present study, the estimates of AAV were lower in magnitude with respect to RIL 96 followed by RIL 52, RIL 29 (Table 4) and hence they are regarded as widely adaptable. Further, the estimate of Adaptability Index (AI) is a useful parameter for objective assessment of adaptability of the genotypes based on both mean dry seed yield/plant and adaptability. The average dry seed yield per plant of RILs at each location is furnished in Table 3. Low magnitude of AI indicates wide adaptability. In the present study, the lower magnitudes of estimates of AI of RIL 1, RIL 52 RIL 96 and RIL 101 suggested their wide adaptation with high mean dry seed yield/plant (Table 4). 
Table 3. Mean of dry seed yield/plant of dolichos bean RILs in each tested locations

\begin{tabular}{lcccc}
\hline RIL & ZARS, Mandya & $\begin{array}{c}\text { Mean of dry seed yield/plant (g) } \\
\text { ARS, Chintamani }\end{array}$ & $\begin{array}{c}\text { College of } \\
\text { Agriculture Hassan }\end{array}$ & $\begin{array}{c}\text { GKVK, } \\
\text { Bengaluru }\end{array}$ \\
\hline RIL 1 & 15.26 & 16.45 & 22.76 & 27.04 \\
RIL 12 & 10.41 & 19.36 & 14.97 & 26.26 \\
RIL 29 & 16.29 & 18.65 & 13.85 & 20.44 \\
RIL 43 & 12.48 & 16.84 & 14.89 & 23.75 \\
RIL 52 & 18.33 & 12.90 & 14.99 & 24.18 \\
RIL 77 & 11.18 & 14.90 & 16.62 & 36.49 \\
RIL 80 & 19.48 & 26.32 & 14.27 & 16.25 \\
RIL 96 & 15.57 & 16.81 & 16.49 & 20.67 \\
RIL 101 & 22.82 & 14.26 & 16.55 & 24.44 \\
RIL 111 & 26.70 & 16.74 & 12.53 & 15.60 \\
\hline
\end{tabular}

Table 4. Estimates of IPC scores and stability parameters to assess adaptability of $\mathbf{1 0}$ recombinant inbred lines (RILs) derived from HA 10-8 $\times$ RIL 3-180 of dolichos bean for dry seed yield/plant

\begin{tabular}{lcccccc}
\hline RILs & $\begin{array}{l}\text { Mean dry } \\
\text { seed yield } \\
\text { per plant } \\
\text { (g) }\end{array}$ & $\begin{array}{c}\text { Rank } \\
\text { based on } \\
\text { mean }\end{array}$ & $\begin{array}{l}\text { AMMI } \\
\text { adaptability } \\
\text { value (AAV) } \\
\text { score }\end{array}$ & $\begin{array}{c}\text { Rank } \\
\text { based on } \\
\text { AAV }\end{array}$ & $\begin{array}{l}\text { Adaptability } \\
\text { index (AI) } \\
\text { score }\end{array}$ & $\begin{array}{c}\text { Rank } \\
\text { based } \\
\text { on AI }\end{array}$ \\
\hline RIL 1 & 20.38 & 1 & 3.12 & 6 & 7 & 1 \\
RIL 12 & 17.75 & 6 & 3.72 & 7 & 13 & 8 \\
RIL 29 & 17.31 & 9 & 1.69 & 3 & 12 & 6 \\
RIL 43 & 16.99 & 10 & 1.95 & 4 & 14 & 8.5 \\
RIL 52 & 17.60 & 7 & 1.31 & 2 & 9 & 3.5 \\
RIL 77 & 19.80 & 2 & 8.91 & 10 & 12 & 6 \\
RIL 80 & 19.08 & 4 & 6.46 & 8 & 12 & 6 \\
RIL 96 & 17.39 & 8 & 0.72 & 1 & 9 & 3.5 \\
RIL 101 & 19.52 & 3 & 2.19 & 5 & 8 & 2 \\
RIL 111 & 17.89 & 5 & 8.03 & 9 & 14 & 8.5 \\
\hline
\end{tabular}

Based on both visual and objective assessment RIL 52 and RIL 96 were found adaptable across all the test locations with relatively high dry seed yield/plant. Hence RIL 52 and RIL 96 could be used in breeding dolichos bean cultivars with wide adaptation.

\section{CONCLUSIONS}

The RILs differed significantly and interacted with the environments represented by locations. IPCA I and IPCA II explained most of the variability attributable to RILs $\times$ location interaction for dry seed yield/plant. The RIL 52 and RIL 96 were found adaptable across all three test locations. 


\section{ACKNOWLEDGEMENT}

The senior author gratefully acknowledges the financial support from University Grants Commission (UGC), New Delhi, India in the form of Rajiv Gandhi National Fellowship (RGNF) for SC candidates [F1-17.1/2015-16/RGNF-2015-17-SC-KAR-24841/(SAIII/Website)] to pursuing PhD degree in the University of Agricultural Sciences, Bengaluru, India

\section{REFERENCES}

Annicchiarico, P. (1992). Cultivar adaptation and recommendation from alfalfa trials in northern Italy. J. Genet. Breed. 46, 269-278.

Byregowda, M., Girish, G., Ramesh, S., Mahadevu, P. and Keerthi, C.M. (2015). Descriptors of dolichos bean (Lablab purpureus L.), J. Food Legumes. 28(3), 203-214.

Farshadfar, E. 2011). Chromosomal localization of the genes controlling adaptation in Agropyron elongatum using AMMI-based simultaneous selection index of yield and stability. Int. J. Plant Breed. 5(2), 80-83.

Gauch, H. G. and Zobel, R. W. (1988). Predictive and postdictive success of statistical analyses of yield trials. Theor. Appl. Genet., 76(1), 1-10.

Lin, C. S. and Binns, M. R. (1988). A method for analyzing cultivar $\times$ location $\times$ year experiments: a new stability parameter. Theor. Appl. Genet. 76, 425-430.

Purchase, J. L., Hatting, H. and Van Deventer, C. S. (2000). Genotype $\times$ environment interaction of winter wheat (Triticum aestivum L.) in South Africa: II. Stability analysis of yield performance. South African J. Plant Soil. 17(3), 101-107.

Ramesh, S. and Byre Gowda, M. (2016). Dolichos bean (Labalab purpureus L. Sweet var. Lignosus) genetics and breeding - present status and future prospects. Mysore J. Agric. Sci. $50(3), 481-500$.

Segherloo, A. E., Sayyed, H. S., Dehghani, H. and Kamran, M. (2010). Screening of superior chickpea genotypes for various environments of Iran using genotype plus genotype $\times$ environment (GGE) bi-plot analysis. J. Plant Breed. Crop Sci. 2(9), 286-292.

Yan, W. and Kang, M. S. (2002). GGE Biplot Analysis: A graphical tool for breeders, geneticists, and agronomists. CRC press.

Yan, W. and Rajcan, I. (2002). Biplot analysis of test sites and trait relations of soybean in Ontario, Crop Sci. 42, 11-20.

Yan, W., Hunt, L. A., Sheng, Q. and Szlavnics, Z. (2000). Cultivar evaluation and megaenvironment investigation based on the GGE biplot. Crop Sci. 40, 597-605. 